Henderson, M. E. K. \& Farmer, V. C. (1955). J. gen. Microbiol. 12, 37-46.

\title{
Utilization by Soil Fungi of $p$-Hydroxybenzaldehyde, Ferulic Acid, Syringaldehyde and Vanillin
}

\author{
By MOIRA E. K. HENDERSON AND V. C. FARMER \\ The Macaulay Institute for Soil Research, Craigiebuckler, Aberdeen
}

SUMMARY: A number of fungi isolated from soils under a variety of vegetational types was found to attack $p$-hydroxybenzaldehyde, ferulic acid, syringaldehyde and vanillin. These compounds were used as sole source of carbon by the organisms tested. By means of spectrochemical methods and paper chromatography it was shown that vanillin and ferulic acid were converted to vanillic acid before the breaking of the benzene ring, and syringaldehyde was converted to syringic acid. The bearing of these results on the breakdown of lignin in soil is discussed.

This investigation was made in connexion with a study of lignin decomposition by soil fungi. Owing to the difficulty of preparing pure lignin extracts, the work was based on the utilization, as carbon sources, of the aromatic compounds $p$-hydroxybenzaldehyde, ferulic acid, syringaldehyde and vanillin (Fig. 1), which are believed to be related structurally to the lignin molecule, the aldehydes having been obtained on its chemical degradation (Brauns, 1952). The fungi were isolated from soils under a variety of vegetational types.<smiles>O=CC1CCC(O)CC1</smiles>

$p$-Hydroxybenzaldehyde<smiles>[R]C1CC(OC)C(O)C(OC)C1</smiles><smiles></smiles><smiles>[R]C(=O)O</smiles><smiles>COC1CC(C=CC(=O)O)CCC1O</smiles>

Ferulic acid<smiles>[R]C1CCC(O)C(OC)C1</smiles><smiles>[R]C=O</smiles><smiles>[R]C(=O)O</smiles>

Fig. 1 


\section{METHODS}

\section{Sampling of soils}

The collection of soil samples had to be modified according to the nature of the profile in the various areas sampled. These ranged from open sand to forest. Where possible, a freshly exposed profile about 8 in. deep was sampled by scraping upwards with a sterilized scoop from a depth of $6 \frac{1}{2}$ to $\frac{1}{2}$ in. The omission of the surface $\frac{1}{2}$ in. was intended to eliminate aerial contaminants not occurring naturally in the soil. The soil was immediately transferred to sterile jars. Each final sample consisted of soil from three profiles dug at random in the area being investigated. Where forest litter was being collected, the fingers were wiped with alcohol prior to picking up litter from the different layers. The samples were stored in a refrigerator until the following day, when dilutions were made.

\section{Isolation of fungi}

Fungi were isolated from the samples by the dilution-plate technique (Brierley, Jewson \& Brierley, 1928), the medium being modified Waksman's agar (Waksman,|1922). The modifications were: (a) replacement of peptone by $\left(\mathrm{NH}_{4}\right)_{2} \mathrm{SO}_{4}$, to decrease the rate of spread of rapidly growing fungi; (b) addition of tannic acid at a concentration of $0 \cdot 1 \%(w / v)$. The second modification was based on the work of Bavendamm (1928) and of Davidson, Campbell $\&$ Blaisdell (1938) who showed that those wood-rotting fungi which are most active in decreasing the lignin content, i.e. the 'white rots', can be differentiated by their reaction with tannic acid which they oxidize to a brown product. A number of other substances give a similar reaction, but tannic acid has the advantages of being only slightly toxic and of inhibiting the growth of most bacteria (Fahreus, 1949).

The plates were incubated at $21 \cdot 5^{\circ}$, and it was possible to remove colonies up to the 10th or 12th day of incubation. Representative isolates from the dilution plates were transferred to potato glucose agar for purification and identification. A selected number of isolates from each soil area sampled were retained in stock cultures on potato glucose agar; they included fungi which did not oxidize tannic acid in addition to those which did.

\section{Cultural conditions}

The basal medium was modified Czapek's mineral salts; sucrose and $\mathrm{FeSO}_{4}$ were omitted, the latter because of its reaction with phenolic compounds to form coloured products. The basal medium thus contained: $\mathrm{NaNO}_{3}, 1 \cdot 5 \mathrm{~g}$; $\mathrm{MgSO}_{4} .7 \mathrm{H}_{2} \mathrm{O}, 0.25$ g.; $\mathrm{KH}_{2} \mathrm{PO}_{4}, 0.5 \mathrm{~g}$.; $\mathrm{KCl}, 0.25 \mathrm{mg}$. in $500 \mathrm{ml}$. water. To volumes of this solution were added, as required, $p$-hydroxybenzaldehyde, syringaldehyde or vanillin at final concentrations of $0.01 \%(\mathrm{w} / \mathrm{v})$, or ferulic acid at $0.005 \%(\mathrm{w} / \mathrm{v})$. The concentrations of the organic compounds in the growth experiments were kept low as they are inhibitory to at least some of the fungi at slightly higher concentrations $(0 \cdot 04 \%, \mathrm{w} / \mathrm{v})$.

Sterilization of the basal medium was by autoclaving and of the phenolic 
compounds by filtration. The medium was dispensed in $10 \mathrm{ml}$. lots in 4 in. diameter Petri dishes. The inocula were uniform $5 \mathrm{~mm}$. diameter disks cut from potato glucose agar plates.

Growth after 24 days at $21 \cdot 5^{\circ}$ was compared with that on similarly inoculated mineral salt basal medium as control. Since the phenolic compounds constituted the sole source of carbon and were present in such low concentrations, none of the fungi produced abundant growth. However, in the majority of cases, growth visibly exceeded that on the control and was correlated with the disappearance of the phenolic compounds from the medium.

Evidence for utilization of phenolic compounds as a source of carbon

In the main series of growth experiments, although the aromatic compounds constituted the sole source of carbon added to the media, it might be claimed that sufficient nutrients to support considerable growth were carried over in the inoculation disk of agar. However, evidence in support of the view that the phenolic compounds were being utilized as a source of carbon was obtained in the following manner, using Coniothyrium sp. and Hormodendrum sp. Inocula cut from the margins of colonies growing in liquid media containing one of the phenolic compounds were used to inoculate fresh dishes of liquid medium. These inocula were cut at a considerable distance from the original inoculation disk and part of the resulting growth was taken for further inoculation. Such successive transfers were continued at monthly intervals for a period of 4 months; the growth in the presence of the various phenolic compounds greatly exceeded that in the mineral salt controls. As small inocula were taken for the successive transfers, very low amounts of nutrients would be carried from one dish to the next and nutrients to support further growth must have been derived from the medium.

\section{Absorption spectrometry}

The absorption spectra of the culture media provided a rapid means for surveying the metabolism of a large number of fungi. The disappearance of the originally added phenolic compounds was readily followed, and where the metabolic products had absorption in the ultraviolet region, their nature was often indicated; in the case of vanillic and syringic acids, they were positively identified. The procedure was as follows. After 24 days at $21 \cdot 5^{\circ}$ the culture media were removed from the dishes and restored to their original volumes of $10 \mathrm{ml}$. They were then diluted 10 times and their absorption spectra measured in both acid ( $\left(0.05 \mathrm{~N}_{-} \mathrm{H}_{2} \mathrm{SO}_{4}\right)$ and alkaline (0.05 $\left.\mathrm{N}-\mathrm{NaOH}\right)$ solutions, in the range 400 to $240 \mathrm{~m} \mu$. The lower wavelength was set by the absorption of the mineral salts in the medium.

In the interpretation of the results, the following situations arose:

(a) No measurable absorption, indicating that no aromatic compounds remained in the culture medium.

(b) Absorption identical with that of the original substrates : their identification and estimation was then certain and accurate. 
(c) Absorption of vanillin and ferulic acid completely replaced by that of vanillic acid, and that of syringaldehyde by syringic acid: their identification and estimation were also certain and accurate.

(d) Absorption corresponding to a mixture of (i) vanillin and vanillic acid, (ii) syringaldehyde and syringic acid, or (iii) ferulic and vanillic acids. The identification of the metabolic products was then less certain but reasonable. Care was taken that the whole absorption spectrum in both acid and alkaline solution was consistent with this interpretation.

The absorption maxima of the pairs (i) and (ii) above are well separated in alkaline solution (Lemon, 1947) and so their concentration was readily estimated. It was not possible, however, to identify and estimate with any certainty the presence of small amounts of vanillic acid associated with ferulic acid (absorption maxima 298 and $345 \mathrm{~m} \mu$ respectively in the alkaline solution).

(e) Absorption appeared which could not be ascribed to the above compounds alone. When present, this absorption was usually of a weak diffuse nature and did not interfere with the estimation of the residual amounts of phenolic compound originally added. The presence of vanillic and syringic acids, however, could not be established with any certainty, although a figure could be given for the maximum concentration likely to be present.

\section{Paper chromatography}

Flasks $(250 \mathrm{ml}$.) containing $100 \mathrm{ml}$. medium were inoculated with five disks cut from potato-glucose agar plates and incubated at $21.5^{\circ}$ for periods of 7 and 14 days. The resulting growth was removed by filtration and the filtrate acidified. Thereafter the filtrate was extracted 3 times with $10 \mathrm{ml}$. ether. The ether was removed by evaporation and the residue dissolved in a few drops of absolute ethanol. The spots were applied to Whatman no. 1 filter-paper by means of a capillary pipette, each extract being spotted 8 times.

The papers were developed with a single-phase mixture based on Long, Quayle \& Stedman (1951), consisting of $n$-butanol/ammonia (sp.gr. 0.880)/ water $\left(80 / 5 / 15\right.$ vol.). They were run for $16 \mathrm{hr}$. at $21^{\circ}$ using the descending method. To separate ferulic and vanillic acids it was necessary to run the papers for $28 \mathrm{hr}$. Duplicate papers were run each time, one being sprayed with 2:4-dinitrophenylhydrazine (Bland, 1949) to trace the aldehydes, the other with diazotized sulphanilic acid (Bray, Thorpe \& White, 1950) to reveal the acids and any other phenolic compounds.

\section{RESULTS}

\section{Growth experiments}

A total of sixty-one isolates, representative of those fungi isolated from ten different soil areas, was studied (Table 1). With the exception of two Mucor isolates these were all Fungi Imperfecti. No ascomycetes or basidiomycetes were identified among the organisms isolated, although some may have been present among a number of unidentified non-sporing fungi.

Spectrochemical analyses of the media at the end of the growth experiments 
Table 1. List of organisms (genera) studied and the substrata from which they were isolated

Numbers in brackets indicate the number of isolates.

Organism

Acrostalagmus (1)

Alternaria (1)

Aspergillus (2)

Botrytis (2)

Cephalosporium (3)

Chaetomella (2)

Coniothyrium (2)

Cylindrocarpon (1)

Fusarium (1)

Gliocladium (1)

Haplographium (1)

Hormiscium (2)

Hormodendrum (5)

Monilia (1)

Mucor (2)

Papularia (1)

Penicillium (15)

Pullularia (1)
Pyrenochaeta (1)
Sphaeronaema (1)
Spicaria (1)
Sporotrichum (2)
Tilachlidium (1)
Torula (2)
Trichoderma (3)
Trichosporium (1)
Verticillium (2)
Unidentified (3)

Location

Agricultural soil

Corsican Pine litter

Foreshore sand; garden soil

Fixed dune sand; heath soil

(Scots Pine humus; peat

Foreshore sand

Ammophila dune sand; fixed dune sand

Scots Pine litter; foreshore sand

Deciduous wood soil

Ammophila dune sand

Agricultural soil

Deciduous wood soil

Deciduous wood soil; Ammophila dune sand

(Sand under Scots Pine (afforested sand dune);

\{garden soil; foreshore sand (2); peat

Heath soil

Foreshore sand; Corsican Pine humus

Fixed dune sand

Foreshore sand; Ammophila dune sand; Dune heath

soil; fixed dune sand (2); Corsican Pine humus;

l heath sand; Scots Pine humus; peat (3); moor soil(4)

Scots Pine litter

Ammophila dune sand

Ammophila dune sand

Foreshore sand

Heath soil (2)

Ammophila dune sand

Heath soil; pasture soil

(Sand under Corsican Pine (afforested sand dune):

Corsican Pine humus; deciduous wood soil

Foreshore sand

Garden soil ; foreshore sand

Scots Pine litter; peat; Ammophila dune sand

revealed that the majority of the fungi decomposed these aromatic compounds to a certain extent. The amounts of substrate remaining after a 24-day period of incubation are listed in Table 2.

Examination of this table shows that the most active organisms were Alternaria sp., Aspergillus sp., Chaetomella sp., Coniothyrium sp., Cylindrocarpon sp., Hormiscium spp., Hormodendrum spp., Penicillium sp. (no. 8), Pyrenochaeta sp., Sphaeronaema sp. and Torula spp., which caused complete disappearance of the benzene ring of all four compounds during the course of the experiment. It can also be seen that some fungi attacked the different compounds to a different extent. $p$-Hydroxybenzaldehyde was the most readily attacked, being removed by all organisms with the exception of unidentified organism no. 3 and a Mucor sp. Syringaldehyde was not as readily available as vanillin, a number of fungi completely altering vanillin, but leaving considerable quantities of syringaldehyde, namely Aspergillus sp. (no. 2), Botrytis sp. (no. 2), Cephalosporium spp. (nos. 1 and 3), Haplographium sp., 
Table 2. Residual amounts of phenolic compounds added initially, and amounts of products from them, after growth of various fungi for 21 days at $21.5^{\circ}$ on mineral salt basal medium + given carbon compound

$p$-Hydroxybenzaldehyde $(0.01 \%, \mathrm{w} / \mathrm{v}$, initially) was completely removed by all organisms tested except (i) Botrytis sp. no. 1 gave an unidentified product with detectable absorption; (ii) Mucor sp. no. 2 gave $\mathbf{0} .0043 \%$ and unidentified organism no. $30.0047 \%$ residual $p$-hydroxybenzaldehyde.

Phenolic compound $(\%, w / v)$ added initially

\begin{tabular}{|c|c|c|c|c|c|c|}
\hline & \multicolumn{2}{|c|}{$\begin{array}{l}\text { Ferulic acid } \\
\quad(0.005)\end{array}$} & \multicolumn{2}{|c|}{$\begin{array}{c}\text { Syringaldehyde } \\
(0.01)\end{array}$} & \multicolumn{2}{|c|}{$\underset{(\mathbf{0} \cdot 01)}{\text { Vanillin }}$} \\
\hline & \multicolumn{6}{|c|}{$\begin{array}{c}\text { Amount of residue of initial substance or of } \\
\text { product after growth }(\%, w / v)\end{array}$} \\
\hline & $\begin{array}{l}\text { Ferulic } \\
\text { acid }\end{array}$ & $\begin{array}{l}\text { Vanillic } \\
\text { acid }\end{array}$ & $\begin{array}{l}\text { Syring- } \\
\text { aldehyde }\end{array}$ & $\begin{array}{l}\text { Syringic } \\
\text { acid }\end{array}$ & Vanillin & $\begin{array}{l}\text { Vanillic } \\
\text { acid }\end{array}$ \\
\hline Acrostalagmus & - & - & - & $<0 \cdot 0010$ & - & - \\
\hline Alternaria & - & - & - & - & - & 一 \\
\hline Aspergillus no. 1 & - & 一 & - & —* & - & - \\
\hline Aspergillus no. 2 & - & $\mathbf{U}^{*}$ & $0 \cdot 0043$ & 0.0047 & - & - \\
\hline Botrytis no. 1 & - & U* & $0 \cdot 001$ & $\mathbf{U}$ & $0 \cdot 0013$ & $<0.002$ \\
\hline Botrytis no. 2 & $<0.001$ & $\mathbf{U} *$ & 0.0051 & $\mathbf{U}$ & - & $<0.0010$ \\
\hline Cephalosporium no. 1 & $0 \cdot 0052$ & Indicated* & 0.0018 & $0 \cdot 006$ & - & 0.011 \\
\hline Cephalosporium no. 2 & 0.0030 & 0.0025 & - & $0 \cdot 010$ & - & 0.0095 \\
\hline Cephalosporium no. 3 & - & - & 0.0048 & $0 \cdot 0060$ & - & - \\
\hline Chaetomella no. 1 & 一 & - & - & U* & - & - \\
\hline Chaetomella no. 2 & - & - & - & 一 & - & - . \\
\hline Coniothyrium no. 1 & - & $<0.0010$ & - & $\mathbf{U}^{*}$ & 一 & - \\
\hline Coniothyrium no. 2 & - & - & - & - & - & $\ldots$ \\
\hline Cylindrocarpon & - & - & 一 & - & - & - \\
\hline Fusarium & - & 一 & 0.002 & $0 \cdot 0023$ & - & - \\
\hline Gliocladium & - & - & - & $0 \cdot 006^{*}$ & - & - \\
\hline Haplographium & 一 & - & 0.0065 & - & - & $\longrightarrow$ \\
\hline Hormiscium no. 1 & - & - & - & - & 一 & - \\
\hline Hormiscium no. 2 & - & - & 一 & - & - & - \\
\hline Hormodendrum no. 1 & - & 一 & - & - & - & - \\
\hline Hormodendrum no. 2 & - & - & - & - & - & - \\
\hline Hormodendrum no. $\mathbf{3}$ & - & - & - & - & - & - \\
\hline Hormodendrum no. 4 & - & - & - & 一 & - & $\ldots$ \\
\hline Hormodendrum no. 5 & - & - & - & - & - & - \\
\hline Monilia & - & $0 \cdot 0023^{*}$ & 0.0090 & - & $0 \cdot 0081$ & 0.0010 \\
\hline Mucor no. 1 & $0 \cdot 0055$ & - & $0 \cdot 0066$ & $<0 \cdot 0010$ & 0.0036 & $\mathbf{U}$ \\
\hline Mucor no. 2 & U* & $\mathbf{U}^{*}$ & $0 \cdot 0022$ & $0 \cdot 0020$ & 0.0025 & $\mathbf{U}^{*}$ \\
\hline Papularia & $<0.0005$ & $\mathbf{U}^{*}$ & - & $<0.001$ & - & - \\
\hline Penicillium no. 1 & - & - & 0.0053 & $0 \cdot 0041$ & - & - \\
\hline Penicillium no. 2 & - & - & 0.0045 & 0.0025 & - & - \\
\hline Penicillium no. 3 & - & 一 & 0.0042 & $0 \cdot 0070$ & - & $\mathrm{U}^{*}$ \\
\hline Penicillium no. 4 & 一 & 一 & 0.0011 & 0.0085 & - & - \\
\hline Penicillium no. 5 & - & - & 0.0027 & 0.0035 & - & - \\
\hline Penicillium no. 6 & - & - & $0 \cdot 0029$ & 0.0060 & - & 一 \\
\hline Penicillium no. 7 & 一 & - & - & 0.0100 & - & - \\
\hline Penicillium no. 8 & - & - & - & - & - & - \\
\hline Penicillium no. 9 & - & - & 0.0073 & 0.0020 & 一 & - \\
\hline Penicillium no. 10 & - & - & - & $0 \cdot 0075$ & - & - \\
\hline Penicillium no. 11 & - & - & 0.0007 & 0.0095 & - & - \\
\hline Penicillium no. 12 & - & - & - & $0 \cdot 0031$ & - & 一 \\
\hline Penicillium no. 13 & - & $\mathbf{U}^{*}$ & $0 \cdot 0061$ & 0.0050 & - & $0.001 *$ \\
\hline Penicillium no. 14 & - & - & - & 0.0055 & - & - \\
\hline
\end{tabular}


Table 2 (cont.)

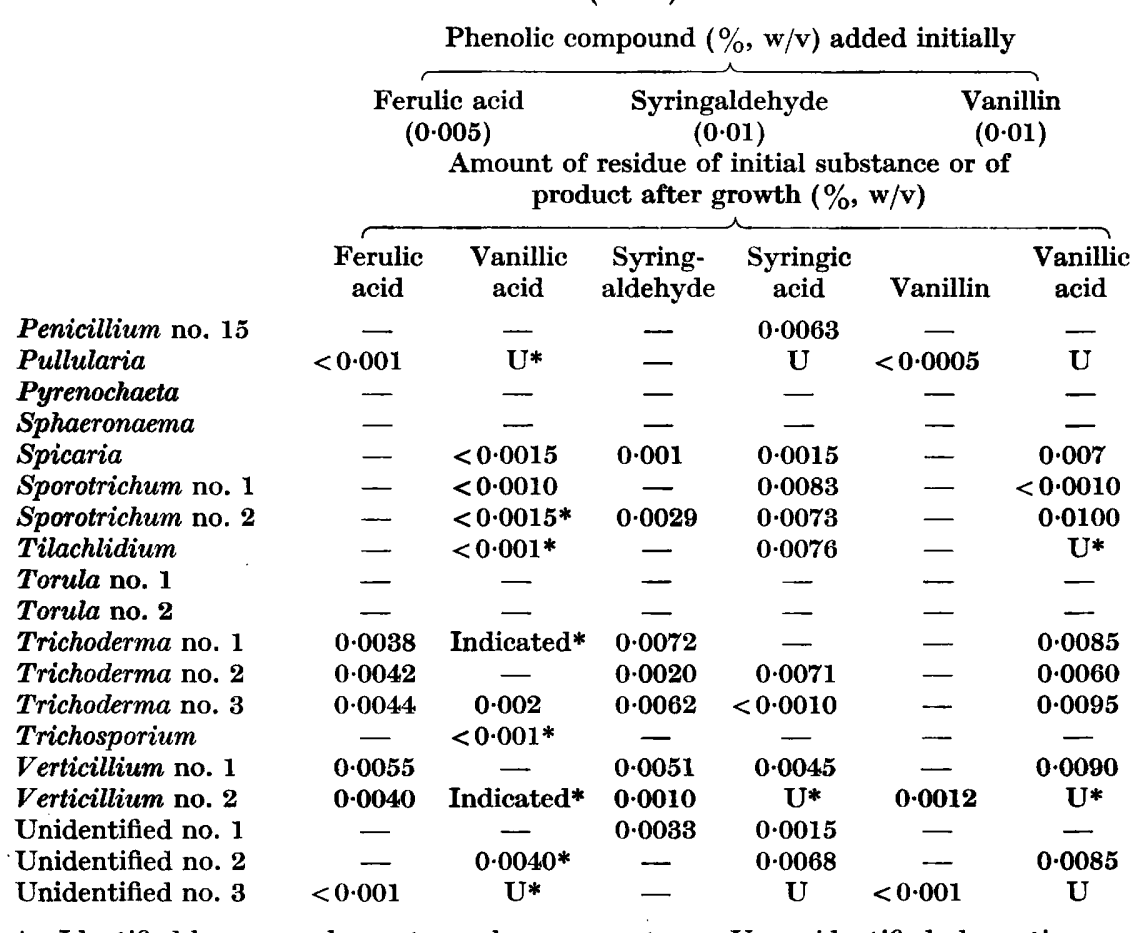

*=Identified by paper chromatography; - = no trace; $\mathrm{U}=$ unidentified absorption.

the majority of Penicillium spp., Sporotrichum sp. (no. 2), Trichoderma spp. (nos. 1-3) and Verticillium sp. (no. 1). Generally, where vanillin was broken down, ferulic acid was also attacked.

\section{Intermediates formed during the breakdown of ferulic acid, syringaldehyde and vanillin}

One intermediate product was traced from each of ferulic acid, vanillin and syringaldehyde; ferulic acid and vanillin were converted to vanillic acid, and the syringaldehyde to syringic acid. No intermediate was traced from $p$-hydroxybenzaldehyde. The ability of the fungi to metabolize the acids further varied considerably, as can be seen from the figures in Table 2 showing the amounts of the acids present after the 24-day growth period. Cephalosporium spp., Sporotrichum sp., Trichoderma spp., Verticillium sp. and unidentified organism no. 2 showed almost quantitative conversion of vanillin to vanillic acid, at which stage metabolism apparently ceased. Spicaria sp. and Trichoderma sp. gave lower residual amounts of vanillic acid, indicating an ability to utilize it at a slow rate. Other fungi, including Hormodendrum sp. (no. 1) and Torula sp. (no. 1) left no residue when grown on vanillin. These two fungi were equally effective in removing the substrate when grown on mineral salts $+0.01 \%(\mathrm{w} / \mathrm{v})$ vanillic acid, whereas Spicaria sp., Trichoderma sp. and unidentified organism no. 2 left considerable quantities of the acids. Syringic 
acid was less readily metabolized, a large number of fungi (in particular Penicillium spp. which removed vanillic acid completely) leaving considerable quantities of syringic acid in the media.

Further analyses were made with Hormodendrum sp. (no. 1) to discover whether it was in fact releasing vanillic and syringic acids as intermediate products in the early stages of growth. Flasks containing $100 \mathrm{ml}$. of medium were inoculated with five disks and $5 \mathrm{ml}$. samples were removed aseptically after different lengths of time for spectrochemical examination. Vanillic acid was identified in the vanillin and ferulic acid cultures, and syringic acid in the syringaldehyde culture. The amounts of the residual substrates and the amounts of vanillic and syringic acids formed are recorded in Table 3; these results were confirmed by paper chromatography. The production of vanillic and syringic acids as intermediate products by the following fungi was also confirmed by paper chromatography: Chaetomella sp. (no. 1), Hormiscium sp. (no. 1), Penicillium sp. (no. 3), Pyrenochaeta sp. and Torula sp. (no. 1). As these fungi are all active in removing the substrates it was necessary to make the chromatographic analyses of the media after a very short growth period.

Table 3. The amounts of the original substrates remaining and of the intermediates formed after Hormodendrum $s p$. had been grown on mineral salts with ferulic acid, syringaldehyde or vanillin at $21 \cdot 5^{\circ}$.

Samples $(5 \mathrm{ml}$.) were removed aseptically for analysis after the stated number of days.

\begin{tabular}{|c|c|c|c|c|c|c|}
\hline & & & npound adde & carbon so & ree & \\
\hline & Ferul & acid & Syring & ayde & Va & illin \\
\hline Period of & $\begin{array}{l}\text { Ferulic- } \\
\text { acid }\end{array}$ & $\begin{array}{l}\text { Vanillic } \\
\text { acid }\end{array}$ & Syringaldeh & $\rightarrow$ Syringic & Vanillin & $\begin{array}{c}\rightarrow \text { Vanillic } \\
\text { acid }\end{array}$ \\
\hline $\begin{array}{l}\text { growth } \\
\text { (days) }\end{array}$ & Co & entratior & $(\%, w / v)$ of & inal substa & ce or pr & luct \\
\hline o & 0.005 & - & 0.01 & - & 0.01 & - \\
\hline 3 & 0.0018 & trace* & No a & ris & No a & alysis \\
\hline 6 & trace & - & 0.0048 & trace & 0.0028 & trace \\
\hline 8 & No a & lysis & 0.0019 & $0.005^{*}$ & 0.002 & $0.0025^{*}$ \\
\hline 14 & 一 & - & - & 0.002 & - & - \\
\hline
\end{tabular}

A number of fungi formed unidentified metabolic products which interfered with the identification of syringic and vanillic acids by absorption spectrometry. The presence of such unidentified absorption is indicated by the letter $\mathrm{U}$ in Table 2. In these instances the culture filtrates were examined by paper chromatography. The results are shown in Table $\mathbf{2}$ where an asterisk indicates that the presence of the acids was in fact established in most cases.

Two exceptions were Pullularia sp. and unidentified organism no. 3, neither of which produced syringic acid from syringaldehyde or vanillic acid from vanillin. It would seem that these fungi attack the compounds in a different manner, indicated by the fact that when grown on syringaldehyde they both colour the solution yellow and on vanillin colour it orange, unidentified 
organism no. 3 on vanillin forming a fine orange precipitate. When grown on ferulic acid they both gave a fine orange precipitate but the presence of very small quantities of vanillic acid was shown by paper chromatography.

Two further exceptions were Botrytis sp. (no. 1) and Trichoderma sp. (no. 1) which instead of forming syringic acid when grown on syringaldehyde gave rise to a substance of low $\boldsymbol{R}_{F}$ value which was detected by diazotized sulphanilic acid.

\section{DISCUSSION}

The data show that there exist in soils under a wide range of vegetational types fungi which can decompose $p$-hydroxybenzaldehyde, ferulic acid, syringaldehyde and vanillin. The fungi studied are representative of those which can be isolated by the dilution-plate technique; not isolated by this technique are the soil basidiomycetes and ascomycetes which should also be studied in order to obtain a true picture of fungal activity in the soil.

The methods of analysis employed, absorption spectrometry and paper chromatography, have shown that the decomposition of these compounds (see Fig. 1) in the majority of cases proceeds as follows:

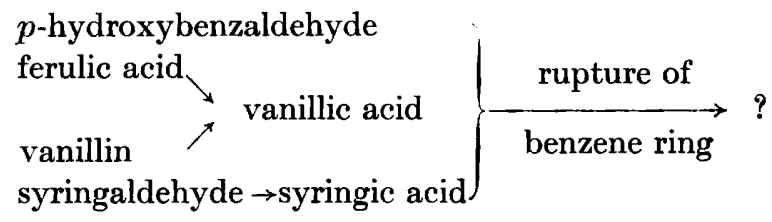

Absorption within the spectral range used does not permit the identification of the products formed following rupture of the benzene ring. Some fungi formed products (in addition to the acids) which appeared on the paper chromatogram, but they have not yet been identified.

As the original soil isolations were based on the ability of the fungi to oxidize tannic acid, it is interesting to compare this property with their activity in the utilization of these compounds. The results showed that of sixty-one fungal isolates studied, thirty-four oxidized tannic acid, and of these fifteen removed the four phenolic compounds completely from the media. Of the twentyseven isolates which did not oxidize tannic acid, two removed the compounds completely. Within these two main groups the numbers of fungi which removed three, two, one or none of the compounds were similar. There would thus seem to be a correlation only between the ability to oxidize tannic acid and the ability to utilize all four of the phenolic compounds tested.

Only a few fungi formed coloured products and precipitates such as are produced by certain wood-rot fungi when grown on some of these compounds. Dion (1952) obtained similar products when he added culture filtrate containing an extracellular enzyme of Polyporus versicolor to solutions of a number of phenols. As tannic acid oxidation depends on the formation of a quinone and as these soil fungi break down the aromatic ring, it seems probable that an enzyme system is involved which is different from the polyphenoloxidase type present in wood-rot fungi and that the correlation between the number of isolates which utilized all four phenolic compounds and the number which 
oxidized tannic acid is probably not significant. Fåhreus (1949) reported oxidation of tannic acid by a soil fungus which was a weak lignin-decomposer and not a true rot fungus. Ledingham \& Adams (1942) found that fungi giving similar reactions with tannic acid varied widely in their ability to decompose lignin in the form of calcium ligno-sulphonate. The ability of soil fungi to utilize the four phenolic compounds tested may constitute a stage in the decomposition of lignin. It has been shown (Henderson \& Farmer, unpublished) that certain wood-rot fungi will release vanillin and vanillic acid from spruce sawdust. It would seem that the combined activities of these different fungi may be concerned in the breakdown of lignin under natural conditions.

We wish to thank Dr D. M. Webley for his advice and assistance and Dr G. K. Fraser for his interest in the work.

\section{REFERENCES}

Bavendamm, W. (1928). Über das Vorkommen und den Nachweis von Oxydasen bei holzzerstörenden Pilzen. Z. PflKrankh. 38, 257.

BLAND, D. E. (1949). Separation of vanillin and syringaldehyde by paper partition chromatography. Nature, Lond. 164, 1093.

Brauns, F. E. (1952). The Chemistry of Lignin. New York: Academic Press.

Bray, H. G., Thorpe, W. V. \& White, K. (1950). The fate of certain organic acids and amides in the rabbit. 10. The application of paper chromatography to metabolic studies of hydroxybenzoic acids. Biochem. J. 46, 271.

Brierley, W. B., Jewson, S. T. \& Brierley, M. (1928). The quantitative study of soil fungi. Proc. and Papers of 1st Int. Congr. Soil Sci. Commission 3, p. 48.

Davidson, R. W., Cambell, W. A. \& Blaisdell, D. J. (1938). Differentiation of wood-decaying fungi by their reactions on gallic or tannic acid medium. J. agric. Res. 57, 683.

Dion, W. M. (1952). Production and properties of a polyphenol oxidase from the fungus Polyporus versicolor. Canad. J. Bot. 30, 9.

FÅHREUS, G. (1949). On the oxidation of phenolic compounds by wood-rotting fungi. LantbrHogsk. Ann. 16, 618.

Ledingham, G. A. \& Adams, G. A. (1942). Biological decomposition of chemical lignin. II. Studies on the decomposition of calcium lignosulphonate by wooddestroying and soil fungi. Canad. J. Res., Sect. C, 20, 13.

LEMon, H. W. (1947). The effect of alkali on the ultraviolet absorption spectra of hydroxyaldehydes, hydroxyketones and other phenolic compounds. J. Amer. chem. Soc. 69, 2998.

Long, A. G., Quayle, J. R. \& Stedman, R. J. (1951). The separation of acids by paper partition chromatography. J. chem. Soc. p. 2197.

Waksman, S. A. (1922). The growth of fungi in the soil. Soil Sci. 14, 153. 